\title{
Obituary: pulmonary artery catheter 1970 to 2013
}

\author{
Paul E Marik
}

\begin{abstract}
The birth of the intermittent injectate-based conventional pulmonary artery catheter (fondly nicknamed PAC) was proudly announced in the New England Journal of Medicine in 1970 by his parents HJ Swan and William Ganz. PAC grew rapidly, reaching manhood in 1986 where, in the US, he was shown to influence the management of over 40\% of all ICU patients. His reputation, however, was tarnished in 1996 when Connors and colleagues suggested that he harmed patients. This was followed by randomized controlled trials demonstrating he was of little use. Furthermore, reports surfaced suggesting that he was unreliable and inaccurate. It also became clear that he was poorly understood and misinterpreted. Pretty soon after that, a posse of rivals (bedside echocardiography, pulse contour technology) moved into the neighborhood and claimed they could assess cardiac output more easily, less invasively and no less reliably. To make matter worse, dynamic assessment of fluid responsiveness (pulse pressure variation, stroke volume variation and leg raising) made a mockery of his 'wedge' pressure. While a handful of die-hard followers continued to promote his mission, the last few years of his existence were spent as a castaway until his death in 2013. His cousin (the continuous cardiac output PAC) continues to eke a living mostly in cardiac surgery patients who need central access anyway. This paper reviews the rise and fall of the conventional PAC.
\end{abstract}

Keywords: Pulmonary artery catheter; Right heart catheterization; ICU; Hemodynamic monitoring; Operating room

\section{Review}

Pulmonary artery (PA) catheterization was first performed by Lewis Dexter in 1945 [1]. After observing a spinnaker on a sailboat off Santa Monica beach, the idea of a flow-directed PA catheter (PAC) was developed by Swan and Ganz in 1970, allowing bedside placement [2]. The PAC was subsequently modified with a thermistor to allow measurement of cardiac output (CO) [3]. Shortly after the publication by Swan et al. in 1970, the balloon tipped PA catheter became commercially available and it began to be used in a variety of clinical settings. The use of the PAC moved from the cardiac catheterization laboratory to the ICU and operating room and its use changed from being used as a diagnostic to a therapeutic tool. Clinicians began to use the hemodynamic data derived from the PAC to select, modify and monitor medical treatments. After the introduction of the PAC, enthusiasm for the device increased and its use increased exponentially. Indeed, the PAC became the cornerstone of critical care and a hallmark of the ICU. In the 1980 s $20 \%$ to $40 \%$ of seriously ill

Correspondence: marikpe@evms.edu

Division of Pulmonary and Critical Care Medicine, Eastern Virginia Medical School, 825 Fairfax Avenue, Suite 410, Norfolk, VA, USA patients who were hospitalized were reported to undergo pulmonary artery catheterization [4]. This phenomenon occurred despite that fact that the safety, accuracy, and benefit of the device had never been established.

Eugene Robin was the first clinician to challenge the widespread adoption of the PAC. He wrote two editorials in the mid 1980s in which he called for a moratorium on the use of the PAC until randomized controlled trials (RCTs) were performed which demonstrated the safety and improved outcomes associated with the use of the PAC [5,6]. A decade later the landmark study by Connors and coworkers was published [7]. Using propensity matching, this study demonstrated a $24 \%$ increased risk of death in ICU patients who received a PAC within 24 hours of admission to an ICU. The first large randomized, controlled, prospective, evaluation of the PAC was published by Sandham and colleagues in 2003 [8]. These authors randomized 1,994 high risk patients aged 60 years or older who were scheduled for major surgery to goal directed therapy guided by a PAC compared to standard care without a PAC. Hospital and six month mortality and length of stay were similar between the two groups. Except for pulmonary embolism, which was higher in the PAC group, morbidity was

\section{实}


similar between groups. This was followed by two European studies conducted in critically ill ICU patients and the ESCAPE trial in patients with heart failure which failed to demonstrate any benefit from the PAC [9-11]. A meta-analysis conducted by the Cochrane group demonstrated no benefit from the use of the PAC in high risk surgery patients (eight studies) and general ICU patients (four studies) [12]. In the US, the use of the PAC peaked between 1993 and 1996 with a rate of 5.6 per 1,000 hospital admissions, declining to a rate of 1.99 per 1,000 hospital admissions in 2004 [4]. The decline in the use of the PAC appears to have followed the publication of the Connors study in 1996 [7]. Current utilization of the PAC in ICU's in the US is unknown, with most PACs being placed in patients undergoing cardiothoracic surgery. Despite dramatic reductions in the routine use of the PAC in cardiac surgery to less than $20 \%$ of cases in Europe and less than $10 \%$ in Japan, some centers in North America and Australia still routinely use the device [13,14].

The PAC provides hemodynamic data that cannot be obtained from clinical examination. It was therefore widely believed that the data obtained from the PAC would allow a better understanding of the patients hemodynamic profile and that this would lead to therapeutic interventions which would improve patient outcomes [15]. This premise was based on the assumption that the data obtained from the PAC were accurate, that clinicians were able to interpret the data and that the data themselves were useful in managing critically ill patients. However the evidence suggests that these three assumptions are incorrect. Furthermore, it is likely that information obtained from the PAC triggers inappropriate therapy that may be harmful.

\section{The data provided by the PAC may not be accurate}

The $\mathrm{CO}$ and pulmonary capillary wedge pressure (PCWP) are the hemodynamic parameters obtained from the PAC which are most frequently used to make therapeutic decisions. Furthermore, these variables are used in the calculation of many of the other hemodynamic parameters. However, the inaccuracies of both of these variables essentially preclude them from being used for this purpose.

Adolph Fick described the first method of $\mathrm{CO}$ estimation in 1870 [16]. The direct Fick method was the reference standard by which all other methods of determining $\mathrm{CO}$ were evaluated until the introduction of the PAC. Currently the PAC is considered the 'Gold Standard' against which other devices are compared. Despite the ubiquitous use of the PAC, remarkably few studies have investigated the accuracy of the CO measurements as determined by thermodilution. In 1982 Stetz and colleagues analyzed the reliability of the PAC and reported a precision of $15 \%$; that is, there must be a minimal difference of $15 \%$ between determinations of $\mathrm{CO}$ (three measurements per determination) to suggest clinical significance [17]. This study became the reference standard for the PAC, with a precision of $15 \%$ being used in studies evaluating fluid responsiveness. However, more recent studies have been unable to reproduce the findings of Stetz and colleagues. Dhingra and coauthors compared the thermodilution $\mathrm{CO}$ with that measured by the Fick technique over a wide range of cardiac outputs [18]. The bias was $-0.17 \mathrm{~L} / \mathrm{min}$ with the upper and lower limits of agreement being 2.96 $\mathrm{L} / \mathrm{min}$ and $-3.30 \mathrm{~L} / \mathrm{min}$, respectively. The percentage error was $62 \%$. When compared to the direct Fick method the PAC has a percentage error of 56 to $83 \%$ [18-20]. The percentage error $(2 \mathrm{SD} / \mu)$ is derived by the Bland-Altman method with a percentage error of up to $30 \%$ being considered clinically acceptable [21]. Philips et al. compared thermodilution $\mathrm{CO}$ with surgically implanted ultrasonic flow probes in an ovine model [22]. The percentage bias and precision was $-17 \%$ and $47 \%$ respectively; the PAC under-measured dobutamineinduced CO changes by $20 \%$ (relative 66\%) compared with the flow probe. This study found that the PAC was an inaccurate measure of $\mathrm{CO}$ and was unreliable for detection of CO changes less than $30 \%$. Critchely et al., using a similar methodology in pigs, reported a precision of $26 \%$ [23]. These studies suggest that the true CO has to change by at least $25 \%$ to be detected by the PAC. Furthermore, the required change may be as high as $100 \%$ depending on the monitor being used [24].

It is likely that multiple factors interact to affect the accuracy of the thermodilution CO calculation [25]. Occult warming of cold indicator before injection can produce indicator loses leading to overestimates of $\mathrm{CO}$. Significant losses of thermal indicator arise from the dissipation of cold indicator through the intravascular portions of the catheter which have been pre-warmed by the surrounding blood. Spontaneous or mechanical ventilation affects the actual $\mathrm{CO}$; the SV can vary by as much as $50 \%$ at various phases of the respiratory cycle $[26,27]$. The averaging of multiple measurements at different phases of the respiratory cycle has therefore been proposed. It is unclear how many measurements are needed for sufficient accuracy and reproducibility, but it seems that three, although clinically mostly performed, is insufficient. PA thermodilution $\mathrm{CO}$ measurements are unreliable in the presence of tricuspid regurgitation. In general $\mathrm{CO}$ is underestimated in patients with tricuspid regurgitation [28-30]. This finding is important as the incidence of tricuspid regurgitation is about $15 \%$ in the general population increasing to greater than $70 \%$ in elderly patients [31-33]. It should be noted that the reproducibility of $\mathrm{CO}$ measurements by 
transpulmonary thermodilution appears significantly better than that of the PAC with a precision of about $7 \%$ $[34,35]$. The better precision of transpulmonary thermodilution compared to the PAC is probably related to the longer transit time of the thermal bolus which is not influenced by respiration and arrhythmias.

In addition to providing $\mathrm{CO}$ data that are inaccurate, a number of factors may lead to erroneous PCWP measurements. The accurate and consistent placement of pressure transducers for invasive monitoring is critically important. Errors in zeroing and obtaining baseline measurements are exceedingly common and may result in changes in the PA and PCWP pressure of up to $6 \mathrm{mmHg}$ $[36,37]$. Furthermore the patient's position is frequently not standardized, leading to further errors in measurement [38]. Figg and Nemergut demonstrated significant variation in transducer placement for central venous pressure (CVP) measurement amongst perioperative health care providers [39]. Damped tracings and catheter 'fling' may not be recognized, leading to erroneous measurements [38]. These errors are compounded in patients on mechanical ventilators where the use of positive pressure ventilation, spontaneous breaths and the use of positive end expiratory pressure (PEEP) make analysis of the PCWP challenging and unreliable $[36,40,41]$.

\section{Risks from the PAC itself}

The complications that may arise directly from the use of the PAC include pulmonary artery rupture, pulmonary artery thrombosis, intra-cardiac knotting of the catheter, pulmonary hemorrhage, right atrial thrombosis, catheter related bloodstream infection, internal jugular/ subclavian vein stenosis or thrombosis, atrial and ventricular arrhythmia, electromechanical dissociation and right-sided endocarditis. These risks may not be trivial. A study of 70 critically ill patients demonstrated that $4 \%$ died from complications related to the PAC and that between 20 and $30 \%$ had major complications related to the PAC [42]. Fatal air embolism related to the PAC introducer has also been reported [43-45].

\section{Harm due to knowledge deficit}

Studies suggest that clinicians are unable to correctly interpret the data obtained from the PAC even if one assumes that these measurements are accurate. A 1990 study by Iberti et al., in which a 31-item examination on the PAC was completed by 496 North American 'intensivists' found that only $67 \%$ of the answers were correct [46]. The instrument yielded similar results in Europe [47]. A 1996 survey of more than 1,000 critical care physicians found that, although $83 \%$ of questions were answered correctly, a third of the respondents could not correctly identify the PCWP on a clear tracing and could not identify the major components of oxygen transport [48]. Large interobserver variability has been reported in the interpretation of PAC pressure tracings with little agreement between 'experts' [49-51]. A survey of practicing cardiac anesthesiologists concluded that 'a large proportion of anesthesiologists who use the PAC disagree about PCWP estimation, and even those who agree may lack the confidence necessary to use it effectively' [52]. What is most disturbing is that when board certified intensivists are provided with the same PAC data there is enormous variability in the intervention consequent to 'interpretation' of the data [51]. Remarkably, while clinicians acknowledge that 'other practitioners' have a poor understanding on the PAC and the interpretation of the 'hemodynamic profile' derived from the PAC, they believe that they have a good understanding of the PAC and that in their 'hands' the PAC is a useful and beneficial device [51-53]. Similar problems concerning a 'knowledge deficit' have been identified among critical care nurses [54]. Johnson and colleagues using the same questionnaire as Iberti et al. in a cohort of ICU nurses demonstrated only $42 \%$ of questions were answered correctly [55]. In this study, 51\% of respondents were unable to correctly identify the pressure change as the catheter was advanced from the right ventricle to the PA. It is clear that this 'knowledge deficit' is a major factor contributing to the lack of benefit (? harm) of the PAC.

\section{The data obtained from the PAC may not be useful in managing critically ill patients}

A major factor explaining the lack of benefit of the PAC may be that the data obtained are not useful in managing critically ill patients. A commonly cited benefit of the PAC is that it provides filling pressures which can be used to identify fluid responsiveness and guide fluid administration [15]. However, these filing pressures have been found to be neither uniformly accurate nor effective for fluid guidance. The PCWP suffers from the same limitation as the central venous pressure (CVP) [56,57]. Multiple studies have shown a poor relationship between the PCWP and circulating blood volume, SV and left ventricular end-diastolic volume [58-63]. Furthermore, the PCWP is unable to predict fluid responsiveness [64-66]. These data indicate that the PCWP should not be used to make decisions regarding fluid management. Furthermore, due to the inherent inaccuracy of the $\mathrm{CO}$ measurement the change in the SV following a fluid bolus cannot be used to determine fluid responsiveness nor construct a Frank-Starling curve. An increase in SV of 10 to $15 \%$ is used to define fluid responsiveness [66]. This threshold is significantly below the ability of the PAC to detect a change in $\mathrm{CO}$ [22]. In addition to its inability to determine fluid responsiveness the $\mathrm{CO}$ itself 
has very little utility in guiding patient management. Attempts at increasing $\mathrm{CO}$ and/or achieving supranormal levels of oxygen delivery in medical patients have universally failed to positively impact patient outcome $[9,12,67]$. Indeed, the study by Hayes and colleagues demonstrated that such an approach is harmful [68]. 'Paradoxically', Morelli et al. demonstrated that in the setting of septic shock, the use of a beta-blocker which reduced $\mathrm{CO}$ and oxygen delivery improved patient survival [69].

\section{The PAC results in 'overtreatment'}

Survey studies in postoperative and ICU patients have demonstrated that the PAC provided 'new information' or seemed to change therapy in 30 to $62 \%$ of cases [70-72]. However, the clinical significance of these changes is uncertain and in the absence of demonstrated benefit it is likely that many of these interventions were not beneficial. Fellahi et al. demonstrated a significant independent increase in cardiac morbidity and inhospital mortality in cardiac surgical patients who received dobutamine to improve $\mathrm{CO}$ based on PAC values [73]. Sandison et al. compared the outcome of patients undergoing non-elective abdominal aortic aneurysm repair in two different centers [74]. In the one center, PACs were inserted in $96 \%$ of cases versus $18 \%$ in the other. The patients in the center with higher PAC usage received more crystalloid, colloid and inotropes. Their incidence of renal failure was noted to be higher as were their lengths of stay in both ICU and hospital. These data suggest that placement of a PAC may result in excessive and inappropriate therapeutic interventions that have the potential to harm patients.

\section{Potential benefits of the PAC}

The benefits of the PAC are somewhat difficult to define. In some patients the diagnosis between non-cardiogenic and cardiogenic pulmonary edema is difficult to make. In such circumstance the PCWP has been used to make this distinction. However, with advancements in echocardiography, catheterization of the pulmonary artery for this purpose is seldom required. It would appear that the role of the PAC is limited to diagnosing patients with pulmonary hypertension and managing these patients in the perioperative period (see below), as well as the diagnosis of intracardiac shunts (echocardiography may be better) and amniotic fluid embolism [75].

\section{Indications for the use of the PAC}

Doppler echocardiography is frequently used to calculate the pulmonary artery systolic pressure (sPAP). However, the sPAP as determined by Doppler echocardiography is an inaccurate estimate of sPAP, [76,77] and this technology is not considered a reliable method for the diagnosis and management of pulmonary arterial hypertension (PAH) [78]. Pulmonary artery catheterization is therefore required to confirm the diagnosis of $\mathrm{PAH}$, classify $\mathrm{PAH}$, assess its severity and to test the vasoreactivity of the pulmonary circulation $[79,80]$. Pulmonary artery catheterization has been recommended in patients with significant PAH (sPAP > $50 \mathrm{mmHg}$ and/or RV enlargement) undergoing a major surgical intervention [81]. While this recommendation is not supported by high quality evidence, it would appear to be logical as the PA pressure is the only reliable hemodynamic parameter derived from the PAC and its use may allow for the rational titration of vasoactive agents.

Over 30 randomized controlled trials have studied perioperative hemodynamic optimization in a variety of settings, using various goals and techniques of hemodynamic optimization [82-84]. This approach has been demonstrated to reduce the risk of complications and mortality in elective non-cardiac surgery patients [82-84]. The initial preemptive hemodynamic studies used the PAC and targeted 'supranormal' goals while more recent studies have 'optimized' $\mathrm{CO}$ using esophageal Doppler or dynamic indices of fluid responsiveness. Meta-analyses of these studies have demonstrated that both approaches reduce surgical mortality and morbidity [82-84]. In addition, these meta-analyses have demonstrated that the PAC has been largely replaced by less invasive hemodynamic monitoring techniques.

\section{Conclusions}

There is no evidence that the use of the PAC has improved patient outcomes. There are, however, convincing data that the hemodynamic parameters obtained from the PAC are inaccurate, are incorrectly interpreted and that these data frequently lead to excessive and inappropriate therapeutic interventions that maybe harmful. In addition, the data suggest that the hemodynamic parameters obtained from the PAC have little utility in managing critically ill patients in the ICU and operating room. These data therefore suggest that the PAC has a limited role in the ICU and operating room and challenge those experts who believe that the 'pulmonary artery catheter is still a valuable tool for hemodynamic monitoring' [85]. The PAC, however, has a role in the diagnosis and operative management of patients with pulmonary hypertension and acute right ventricular failure.

\section{Abbreviations}

PCWP: Pulmonary capillary wedge pressure; CO: Cardiac output; PAC: Pulmonary artery catheter; RCT: Randomized controlled trial; PA: Pulmonary artery; CVP: Central venous pressure; PEEP: Positive end expiratory pressure; SV: Stroke volume; sPAP: Pulmonary artery systolic pressure; PAH: Pulmonary artery hypertension; RV: Right ventricle. 


\section{Competing interests}

The author has no financial interest in any of the products mentioned in this paper.

Received: 2 September 2013 Accepted: 21 November 2013

Published: 28 November 2013

\section{References}

1. Dexter L, Haynes FW, Burwell CS, Eppinger EC, Seibel RE, Evans JM: Studies of congenital heart disease, I: technique of venous catheterization as a diagnostic procedure. J Clin Invest 1947, 26:547-553.

2. Swan HJ, Ganz W, Forrester J, Marcus H, Diamond G, Chonette D: Catheterization of the heart in man with use of a flow-directed balloon-tipped catheter. N Engl J Med 1970, 283:447-451.

3. Ganz W, Donosco R, Marcus HS, Forrester JS, Swan HJ: A new technique for measurement of cardiac output by thermodilution in man. Am J Cardiol 1971, 27:392-396.

4. Wiener RS, Welch HG: Trends in the use of the pulmonary artery catheter in the United States, 1993 to 2004. JAMA 2007, 298:423-429.

5. Robin ED: Death by pulmonary artery flow directed catheter, time for a moratorium? Chest 1987, 92:727-731.

6. Robin ED: The cult of the Swan-Ganz catheter. Overuse and abuse of the pulmonary flow catheters. Ann Intern Med 1985, 103:445-449.

7. Connors AF, Speroff T, Dawson NV, Thomas C, Harrell FE, Wagner D, Desbiens N, Goldman L: The effectiveness of right heart catheterization in the initial care of critically ill patients. JAMA 1996, 276:889-897.

8. Sandham JD, Hull RD, Brant RF, Knox L, Pineo GF, Doig CJ, Laporta DP, Viner $S$, Passerini L, Devitt $H$, Kirby A, Jacka M: A randomized, controlled trial of the use of pulmonary-artery catheters in high-risk surgical patients. N Engl J Med 2003, 348:5-14.

9. Richard C, Warszawski J, Anguel N, Deye N, Combes A, Barnoud D, Boulain T, Lefort Y, Fartoukh M, Baud F, Boyer A, Brochard L, Teboul JL, French Pulmonary Artery Catheter Study Group: Early use of the pulmonary artery catheter and outcomes in patients with shock and acute respiratory distress syndrome: a randomized controlled trial. JAMA 2003, 290:2713-2720.

10. Harvey S, Harrison DA, Singer M, Ashcroft J, Jones CM, Elbourne D, Brampton W, Williams D, Young D, Rowan K: Assessment of the clinical effectiveness of pulmonary artery catheters in management of patients in intensive care (PAC-Man): a randomized controlled trial. Lancet 2005, 366:472-477.

11. Binanay C, Califf RM, Hasselblad V, O'Connor CM, Shah MR, Sopko G, Stevenson LW, Francis GS, Leier CV, Miller LW: Evaluation study of congestive heart failure and pulmonary artery catheterization effectiveness: the ESCAPE trial. JAMA 2005, 294:1625-1633.

12. Harvey S, Young D, Brampton W, Cooper AB, Doig G, Sibbald W, Rowan K: Pulmonary artery catheters for adult patients in intensive care. Cochrane Database Syst Rev 2006, 3:CD003408.

13. Ranucci M: Which cardiac surgical patients can benefit from placement of a pulmonary artery catheter? Crit Care 2006, 10(Suppl 3):S6.

14. Handa F, Kyo SE, Miyao H: Reduction in the use of pulmonary artery catheter for cardiovascular surgery [Japanese]. Masui - Jap J Anesthesiol 2003, 52:420-423.

15. Connors AF, MCCaffree DR, Gray BA: Evaluation of right-heart catheterization in the critically ill patient without acute myocardial infarction. N Engl J Med 1983, 308:263-267.

16. Fick A: Ueber die Messung des Blutquantums in den Herzventrikeln. Sitzungsberichte der Physiologisch-Medizinosche Gesellschaft zu Wuerzburg 1870, 2:16.

17. Stetz CW, Miller RG, Kelly GE, Raffin TA: Reliability of the thermodilution method in the determination of cardiac output in clinical practice. Am Rev Respir Dis 1982, 126:1001-1004.

18. Dhingra VK, Fenwick JC, Walley KR, Chittock DR, Ronco JJ: Lack of agreement between thermodilution and Fick cardiac output in critically ill patients. Chest 2002, 122:990-997.

19. Rich JD, Archer SL, Rich S: Evaluation of noninvasively measured cardiac output in patients with pulmonary hypertension [abstract]. Am J Respir Crit Care Med 2011, 183:A6440.

20. Espersen K, Jensen EW, Rosenborg D, Thomsen JK, Elliasen K, Olsen NV, Kanstrup IL: Comparison of cardiac output measurement techniques: thermodilution, Doppler, CO2-rebreathing and the direct Fick method. Acta Anaesthesiol Scand 1995, 39:245-251.

21. Critchley LA, Critchley JA: A meta-analysis of studies using bias and precision statistics to compare cardiac output measurement techniques. J Clin Monit Comput 1999, 15:85-91.

22. Phillips RA, Hood SG, Jacobson BM, West MJ, Wan L, May CN: Pulmonary artery catheter (PAC) accuracy and efficacy compared with flow probe and transcutaneous Doppler (USCOM): an ovine cardiac output validation. Crit Care Res Pract 2012, 62:1494.

23. Yang XX, Critchley LA, Rowlands DK, Fang Z, Huang L: Systematic error of cardiac output measured by bolus thermodilution with a pulmonary artery catheter compared with that measured by an aortic flow probe in a pig model. J Cardiothorac Vasc Anesth 2013. in press.

24. Yang XX, Critchley LA, Joynt GM: Determination of the precision error of the pulmonary artery thermodilution catheter using an in vitro continuous flow test rig. Anesth Analg 2011, 112:70-77.

25. Reuter DA, Huang C, Edrich T, Shernan SK, Eltzschig HK: Cardiac output monitoring using indicator-dilution techniques: basics, limits, and perspectives. Anesth Analg 2010, 110:799-811

26. Synder JV, Powner DJ: Effects of mechanical ventilation on the measurement of cardiac output by thermodilution. Crit Care Med 1982, 10:677-682.

27. Stevens JH, Raffin TA, Mihm FG, Rosenthal MH, Stetz CW: Thermodilution cardiac output measurement. Effects of the respiratory cycle on its reproducibility. JAMA 1985, 253:2240-2242.

28. Cigarroa RG, Lange RA, Williams RH, Bedotto JB, Hillis LD: Underestimation of cardiac output by thermodilution in patients with tricuspid regurgitation. Am J Med 1989, 86:417-420.

29. Balik M, Pachl J, Hendl J: Effect of the degree of tricuspid regurgitation on cardiac output measurements by thermodilution. Intensive Care Med 2002, 28:1117-1121.

30. Heerdt PM, Blessios GA, Beach ML, Hogue CW: Flow dependency of error in thermodilution measurement of cardiac output during acute tricuspid regurgitation. J Cardiothorac Vasc Anesth 2001, 15:183-187.

31. Singh JP, Evans JC, Levy D, Larson MG, Freed LA, Fuller DL, Lehman B, Benjamin EJ: Prevalence and clinical determinants of mitral, tricuspid, and aortic regurgitation (the Framingham Heart Study). [A published erratum appears in Am J Cardiol 1 Nov 1999;84(9):1143]. Am J Cardiol 1999, 83:897-902.

32. Klein AL, Burstow DJ, Tajik AJ, Zachariah PK, Taliercio CP, Taylor CL, Bailey $K R$, Seward JB: Age-related prevalence of valvular regurgitation in normal subjects: a comprehensive color flow examination of 118 volunteers. J Am Soc Echocardiogr 1990, 3:54-63.

33. Fox ER, Wilson RS, Penman AD, King JJ, Towery JG, Butler KR, McMullan MR, Skelton TN, Mosley TH, Taylor HA: Epidemiology of pure valvular regurgitation in the large middle-aged African American cohort of the atherosclerosis risk in communities study. Am Heart J 2007, 154:1229-1234.

34. Monnet X, Persichini R, Ktari M, Jozwiak M, Richard C, Teboul JL: Precision of the transpulmonary thermodilution measurements. Crit Care 2011, 15:R204.

35. Kiefer N, Hofer CK, Marx G, Geisen M, Giraud R, Siegenthaler N, Hoeft A, Bendjelid K, Rex S: Clinical validation of a new thermodilution system fo the assessment of cardiac output and volumetric parameters. Crit Care 2012, 16:R98.

36. Morris $\mathrm{AH}$, Chapman $\mathrm{RH}$, Gardner RM: Frequency of technical problems encountered in the measurement of pulmonary artery wedge pressure. Crit Care Med 1984, 12:164-170.

37. Bridges EJ, Woods SL: Pulmonary artery pressure measurement: state of the art. Heart Lung 1993, 22:99-111.

38. Brandstetter RD, Grant GR, Estilo M, Rahim F, Singh K, Gitler B: Swan-Ganz catheter: misconceptions, pitfalls, and incomplete user knowledge - an identified trilogy in need of correction. Heart Lung 1998, 27:218-222.

39. Figg KK, Nemergut EC: Error in central venous pressure measurement. Anesth Analg 2009, 108:1209-1211.

40. Nadeau S, Noble WH: Misinterpretation of pressure measurements from the pulmonary artery catheter. Can Anaesth Soc J 1986, 33:352-363.

41. Booker KJ, Arnold JS: Respiratory-induced changes on the pulmonary capillary wedge pressure tracing. Crit Care Nurse 1993, 13:80-88.

42. Fein AM, Goldberg SK, Walkenstein MD, Dershaw B, Braitman L, Lippmann ML: Is pulmonary artery catheterization necessary for the diagnosis of pulmonary edema? Am Rev Respir Dis 1984, 129:1006-1009. 
43. Hartung EJ, Ender J, Sgouropoulou S, Bierl R, Engelhardt W, Engemann R: Severe air embolism caused by a pulmonary artery introducer sheath Anesthesiology 1994, 80:1402-1403.

44. Bristow A, Batjer H, Chow V, Rosenstein J: Air embolism via a pulmonary artery catheter introducer. Anesthesiology 1985, 63:340-342.

45. Doblar DD, Hinkle JC, Fay ML, Condon BF: Air embolism associated with pulmonary artery catheter introducer kit. Anesthesiology 1982, 56:389-391.

46. Iberti TJ, Fischer EP, Leibowitz AB, Panacek EA, Silverstein JH, Albertson TE: A multicenter study of physician's knowledge of the pulmonary artery catheter. Pulmonary Artery Study Group. JAMA 1990, 264:2928-2932.

47. Gnaegi A, Feihl F, Perret C: Intensive care physician's insufficient knowledge of right-heart catheterization at the bedside: time to act? Crit Care Med 1997, 25:213-220.

48. Trottier SJ, Taylor RW: Physicians attitudes toward and knowledge of the pulmonary artery catheter: Society of Critical Care Medicine membership survey. New Horiz 1997, 5:201-206.

49. Komadina KH, Schenk DA, La Veau P: Interobserver variability in the interpretation of pulmonary artery catheter pressure tracings. Chest 1991, 100:1647-1654.

50. Al-Kharrat T, Zarich S, Amoateng-Adjepong Y, Manthous CA: Analysis of observer variability in measurement of pulmonary artery occlusion pressures. Am J Respir Crit Care Med 1999, 160:415-420.

51. Marik PE, Varon J, Heard SO: Interpretation of the pulmonary artery occlusion (wedge) pressure: physicians' knowledge versus the experts' knowledge. Crit Care Med 1998, 26:1761-1763.

52. Jacka MJ, Cohen MM, To T, Devitt JH, Byrick R: Pulmonary artery occlusion pressure estimation: how confident are anesthesiologists? Crit Care Med 2002, 30:1197-1203.

53. Levy MM: Pulmonary capillary pressure. Clinical implications. Crit Care Clin 1996, 12:819-839.

54. Ahrens TS: Is nursing education adequate for pulmonary artery catheter utilization? New Horiz 1997, 5:281-286.

55. Johnston IG, Jane R, Fraser JF, Kruger P, Hickling K: Survey of intensive care nurses' knowledge relating to the pulmonary artery catheter. Anaesth Intensive Care 2004, 32:564-568.

56. Marik PE, Baram M, Vahid B: Does the central venous pressure predict fluid responsiveness? A systematic review of the literature and the tale of seven mares. Chest 2008, 134:172-178.

57. Marik PE, Cavallazzi R: Does the central venous pressure (CVP) predict fluid responsiveness: an update meta-analysis and a plea for some common sense. Crit Care Med 2013, 41:1774-1781.

58. Calvin JE, Driedger AA, Sibbald WJ: Does the pulmonary capillary wedge pressure predict left ventricular preload in critically ill patients? Crit Care Med 1981, 9:437-443.

59. Calvin JE, Driedger AA, Sibbald WJ: The hemodynamic effect of rapid fluid infusion in critically ill patients. Surgery 1981, 90:61-76.

60. Hansen RM, Viquerat CE, Matthay MA, Wiener-Kronish JP, DeMarco T, Bathia M, Marks JD, Botvincke EH, Chatterjee K: Poor correlation between pulmonary artery wedge pressure and left ventricular end-diastolic volume after coronary artery bypass graft surgery. Anesthesiology 1986, 64:764-770.

61. Oohashi S, Endoh H, Oohashi S, Endoh H: Does central venous pressure or pulmonary capillary wedge pressure reflect the status of circulating blood volume in patients after extended transthoracic esophagectomy? J Anesth 2005, 19:21-25.

62. Raper R, Sibbald WJ: Misled by the wedge? The Swan-Ganz catheter and left ventricular preload. Chest 1986, 89:427-434

63. Baek SM, Makabaki GG, Bryan-Brown CW, Kusek JM, Shoemaker WC: Plasma expansion in surgical patients with high central venous pressure (CVP); the relationship of blood volume to hematocrit, CVP, pulmonary wedge pressure, and cardiorespiratory changes. Surgery 1975, 78:304-315.

64. Michard F, Teboul JL: Predicting fluid responsiveness in ICU patients: a critical analysis of the evidence. Chest 2002, 121:2000-2008.

65. Osman D, Ridel C, Ray P, Monnet X, Anguel N, Richard C, Teboul JL: Cardiac filling pressures are not appropriate to predict hemodynamic response to volume challenge. Crit Care Med 2007, 35:64-68.

66. Marik PE, Monnet $X$, Teboul JL: Hemodynamic parameters to guide fluid therapy. Ann Crit Care 2011, 1:1.

67. Gattinoni L, Brazzi L, Pelosi P, Latini R, Tognoni G, Pesenti A: A trial of goal-oriented hemodynamic therapy in critically ill patients. N Engl J Med 1995, 333:1025-1032.
68. Hayes MA, Timmins AC, Yau E, Palazzo M, Hinds CJ, Watson D: Elevation of systemic oxygen delivery in the treatment of critically ill patients. N Engl J Med 1994, 330:1717-1722.

69. Morelli A, Ertmer C, Westphal M, Rehberg S, Kampmeier T, Ligges S, Orecchioni A, D'Egidio A, D'Ippoliti F, Mebazaa A, Singer M: Effect of heat rate control with esmolol on hemodynamic and clinical outcomes in patients with septic shock: a randomized clinical trial. JAMA 2013, 16:1683-91.

70. Eisenberg PR, Jaffe AS, Schuster DP: Clinical evaluation compared to pulmonary artery catheterization in the hemodynamic assessment of critically ill patients. Crit Care Med 1984, 12:549-553.

71. Quinn K, Quebbeman EJ: Pulmonary artery pressure monitoring in the surgical intensive care unit. Benefits versus difficulties. Arch Surg 1981 116:872-876.

72. Tuchschmidt J, Sharma OP: Impact of hemodynamic monitoring in a medical intensive care unit. Crit Care Med 1987, 15:840-843.

73. Fellahi JL, Parienti JJ, Hanouz JL, Plaud B, Riou B, Ouattara A: Perioperative use of dobutamine in cardiac surgery and adverse cardiac outcome: propensity-adjusted analyses. Anesthesiology 2008, 108:979-987.

74. Sandison AJ, Wyncoll DL, Edmondson RC, Van HN, Beale RJ, Taylor PR: ICU protocol may affect the outcome of non-elective abdominal aortic aneurysm repair. Eur J Vasc Endovasc Surg 1998, 16:356-361.

75. Gist RS, Stafford IP, Leibowitz AB, Beilin Y: Amniotic fluid embolism. Anesth Analg 2009, 108:1599-1602.

76. Rich JD, Shah SJ, Swamy RS, Kamp A, Rich S: Inaccuracy of Doppler echocardiographic estimates of pulmonary artery pressures in patients with pulmonary hypertension: implications for clinical practice. Chest 2011, 139:988-993.

77. Fisher MR, Forfia PR, Chamera E, Housten-Harris T, Champion HC, Girgis RE, Corretti MC, Hassoun PM: Accuracy of Doppler echocardiography in the hemodynamic assessment of pulmonary hypertension. Am J Respir Crit Care Med 2009, 179:615-621.

78. Rich JD: Counterpoint: can Doppler echocardiography estimates of pulmonary artery systolic pressures be relied upon to accurately make the diagnosis of pulmonary hypertension? No. Chest 2013, 143:1536-1539.

79. Galie N, Hoeper MM, Humbert M, Torbicki A, Vachiery JL, Barbera JA Beghetti M, Corris P, Gaine S, Gibbs JS, Gomez-Sanchez MA, Jondeau G, Klepetko W, Opitz C, Peacock A, Rubin L, Zellweger M, Simonneau G: Guidelines for the diagnosis and treatment of pulmonary hypertension: the Task Force for the Diagnosis and Treatment of Pulmonary Hypertension of the European Society of Cardiology (ESC) and the European Respiratory Society (ERS), endorsed by the International Society of Heart and Lung Transplantation (ISHLT). [A published erratum appears in Eur Heart J. Apr 2011; 32(8):926]. Eur Heart J 2009, 30:2493-2537.

80. Saggar $\mathrm{R}$, Sitbon $\mathrm{O}$ : Hemodynamics in pulmonary arterial hypertension: current and future perspectives. Am J Cardiol 2012, 110:9S-15S.

81. McGlothlin D, Ivascu N, Heerdt PM: Anesthesia and pulmonary hypertension. Prog Cardiovasc Dis 2012, 55:199-217.

82. Hamilton MA, Cecconi M, Rhodes A: A systematic review and meta-analysis on the use of preemptive hemodynamic intervention to improve postoperative outcomes in moderate and high-risk surgical patients. Anesth Analg 2011, 112:1392-1402.

83. Cecconi M, Corredor C, Arulkumaran N, Abuella G, Ball J, Grounds RM, Hamilton M, Rhodes A: Clinical review: goal-directed therapy - what is the evidence in surgical patients? The effect on different risk groups. Crit Care 2013, 17:209.

84. Corcoran T, Rhodes JE, Clarke S, Myles PS, Ho KM: Perioperative fluid management strategies in major surgery: a stratified meta-analysis. Anesth Analg 2012, 114:640-651.

85. Vincent JL, Pinsky MR, Sprung CL, Levy M, Marini JJ, Payen D, Rhodes A, Takala J: The pulmonary artery catheter: in medio virtus. Crit Care Med 2008, 36:3093-3096.

doi:10.1186/2110-5820-3-38

Cite this article as: Marik: Obituary: pulmonary artery catheter 1970 to 2013. Annals of Intensive Care 2013 3:38. 